\title{
INFLUENCE OF THE CRANK MECHANISM POSITION IN THE MOTION OF AN OSCILLATING SIEVE
}

\author{
EMILIAN MOSNEGUTU ${ }^{1}$, NARCIS BARSAN ${ }^{1}$, MIRELA PANAINTE-LEHADUS ${ }^{1}$, \\ DANA CHITIMUS ${ }^{1}$, CLAUDIA TOMOZEI ${ }^{* *}$
}

I "Vasile Alecsandri" University of Bacau, Calea Marasesti 157, Bacau, 600115, Romania

\begin{abstract}
This article presents a study that aims to visualize the influence exerted by the position of the crank mechanism on the motion performed by the sieve supports respectively, on the displacement of an oscillating sieve. The study was oriented for a specific constructive case and involves the connecting rod position changing, the drive mechanism in relation to the horizontal, respectively at the angles $0-75^{\circ}$ and $-45-0^{\circ}$. Also, were identifying the variation of the angle described by the motion of the sieve support. From the obtained results analysis, it was found that in the case of $12.71^{\circ}$ of the connecting rod angle, in relation to the horizontal, the lowest value of the angle described by the motion of the tie rod between the extreme points was obtained. Also, for the value of the connecting rod angle of approximately $6.5^{\circ}$ equal angles described by the extreme positions of the sieve support in relation to the vertical were obtained. It is found that the variation of the connecting rod angle directly influences the variation of the angles described by the connecting rod in relation to the horizontal, the measured value being corresponding to the extreme points $\mathrm{P} 1$ and $\mathrm{P} 2$.
\end{abstract}

Keywords: oscillating motion, crank mechanism, connecting rod angle variation

\section{INTRODUCTION}

A mixture of solid particles, in order to be used in different industrial processes, is subjected to different separation processes, through which the most used is the separation on sieve. Different types of separators are used in the process of solid particle's heterogeneous mixture sieve separation [1-14]. In order, to increase the efficiency of this process, the sieve motions can be ensured by using different devices [15-20]:

- Elliptical motion - used for the purpose of retaining by sieving some coarse particles from a mixture.

- Linear motion - the eccentric is induced on the work surface and a vertical movement, to increase the action of sieving and preventing compaction.

- Circular motion - used for sorting particles in several fractions, depending on thickness and granulation, respectively, or for sifting ground products, with separation according to particle size.

- Centrifugal motion - the most used in the case of particles that have a free flow being used for calibration operations.

- Gyroscopic movement - high efficiency equipment used for long filtration processes of light particles.

From all these methods of sieves entrainment, the most used system is the one with oscillating motion, being found in a series of equipment that performs the process of separating mixtures of solid particles according to their length and width. It is also used in other industrial processes such as packing, grinding or transporting solid particles.

\footnotetext{
* Corresponding author, email: claudia.tomozei@ub.ro

(C) 2021 Alma Mater Publishing House
} 
In this article, a theoretical study was performed to visualize the influence exerted by the position of a crank mechanism used for the movement mechanism of a sieve.

\section{MODELING THE DRIVE MECHANISM}

For the analysis of the influence exerted by the position of the driving mechanism of the sieve on its movement, a sieve was choose performs an oscillating movement (Fig. 1). This system is a classic drive of a sieve block and is composed of [21,22]: sieve; tie rods; Sieve drive mechanism; connecting crank mechanism; fastening element of the sieve connecting rod-crank mechanism.

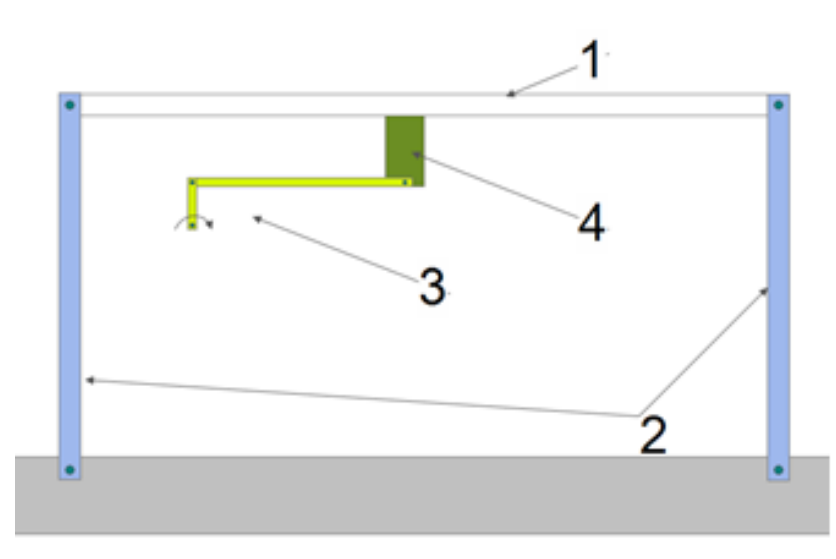

Fig. 1. Sieves block drive system.

The location of the connecting crank mechanism [23], the one that drives, in relation to the gripping joint, varies in a range of $60^{\circ}$. The study was performed for a variation of the work position from $15^{\circ}$ to $15^{\circ}$ (Fig. 2).

Figure 3 shows the variation of the angle generated by the drive device in relation to the gripping joint. The study was performed for values: $-45^{\circ},-30^{\circ},-15^{\circ}, 0^{\circ}, 13^{\circ}, 30^{\circ}, 45^{\circ}, 60^{\circ}, 75^{\circ}$.

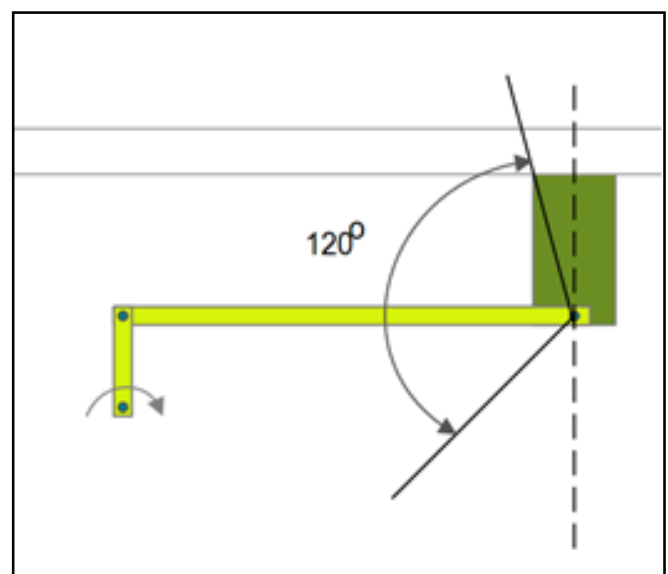

Fig. 2. Variation of the position of the drive system.

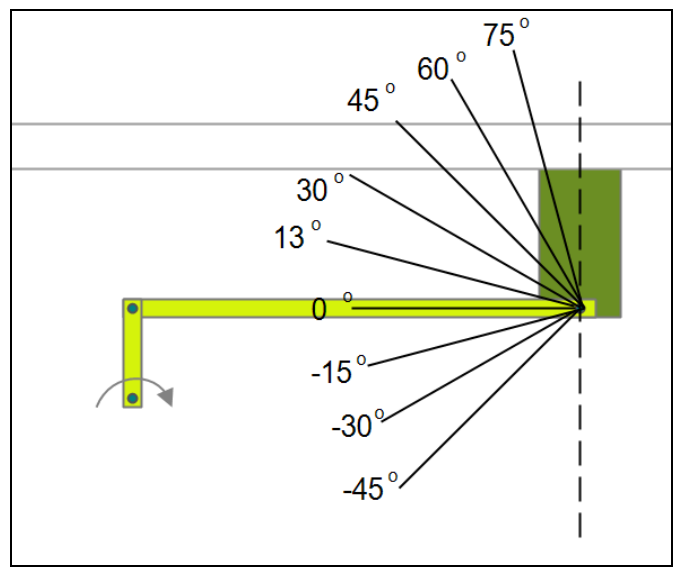

Fig. 3. Variation of the connecting rod position.

For positions $-60^{\circ}$ and $-75^{\circ}$, the study could not be performed because from a physical point of view the movement cannot be performed, respecting the positioning of the crank. It is known that the entire drive mechanism of the seat block is composed of the two components: tie rods and the drive mechanism (connecting rod-crank mechanism). Thus, it was concluded that this assembly can be done in a simplified way. Figure 4 shows the model used in this paper [24, 25].

To determine in value terms, the influence exerted by the position of the drive device, a model was generated whose dimensions are (Fig. 5): tie rods (2): $0.587 \mathrm{~m}$; crank: $0.065 \mathrm{~m}$; connecting rod: $0.27 \mathrm{~m}$. 
The following programs were used to conduct this study:

- The simulation program of mechanisms, Linkage, was used to identify the influence exerted by the position of the connecting rod-crank mechanism on the movements exerted by the free end of the tie rod;

- $\quad$ The Mathcad program used to process the values obtained.

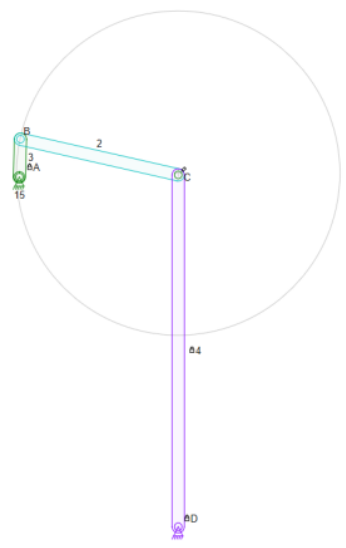

Fig. 4. Simplified model of the analyzed mechanism.

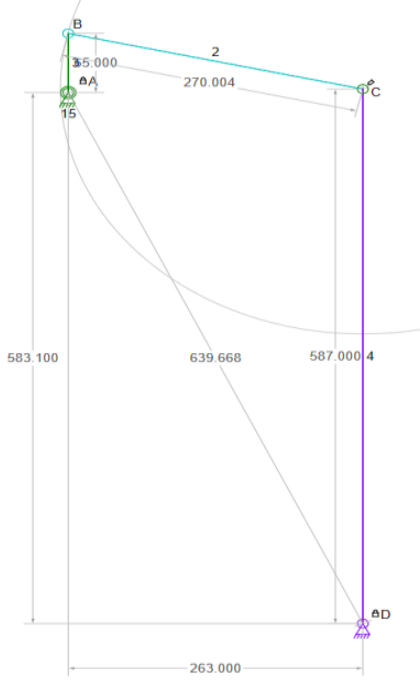

Fig. 5. Dimensional representation of the drive system studied.

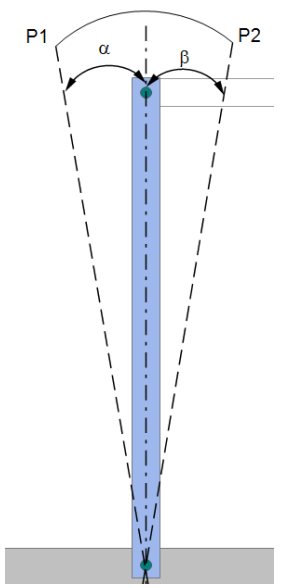

Fig. 6. The movements of the tie rod.

As a result of the processing of the obtained data, the following parameters were identified:

- The angle achieved by the movement of the free end of the tie rod, angle obtained by summing the angles $\alpha$ and $\beta$ (Figure 6).

- The angles made by the connecting rod corresponding to the two extremes of the movement made by the free end of the tie rod.

For each position of the drive device, the angle made by the tie rod was determined. For this purpose, the extreme positions of the tie rod were identified and the values of the angles $\alpha$ and $\beta$ were determined (Figure 6).

Figure 7 shows the working mode for processing the data obtained in order to determine the parameters studied.

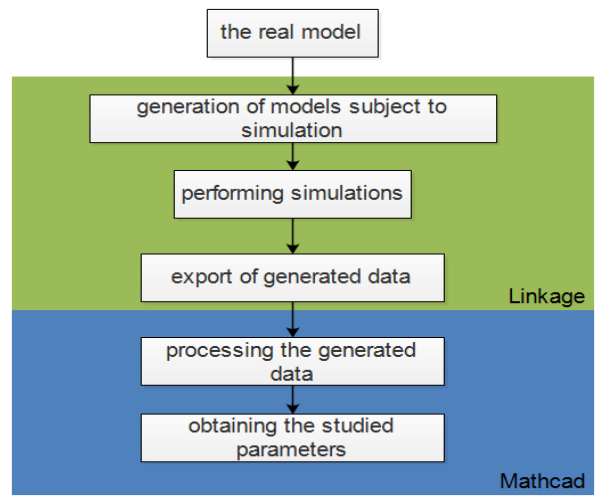

Fig. 7. Working methodology. 


\section{RESULTS AND DISCUSSION}

Following the simulations with the help of the Linkage program, a series of variations of the angles given by the support system of the sieve, respectively of the tie rod were obtained (Figure 8). The graphical representation of these variations was made taking into account the position that the tie rod, the support system of the site, have in the starting position. Compared to these working positions, the movement made by the tie rod was performed for a complete stroke of the crank. The physical value of the extreme points of the free end displacement of the tie rod (P1 and P2) were used for the graphical representations in Figure 8.

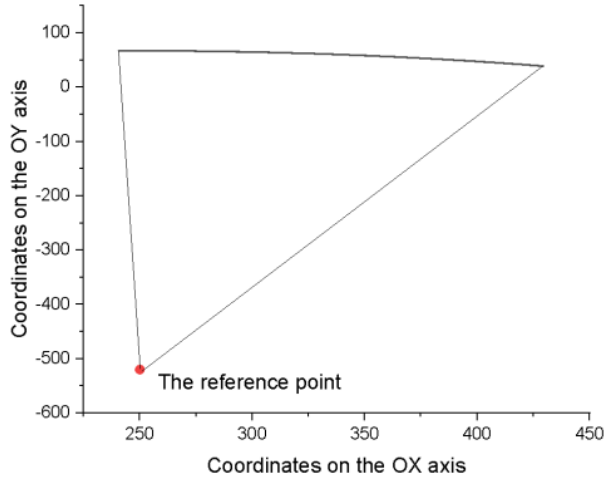

a) $75^{\circ}$

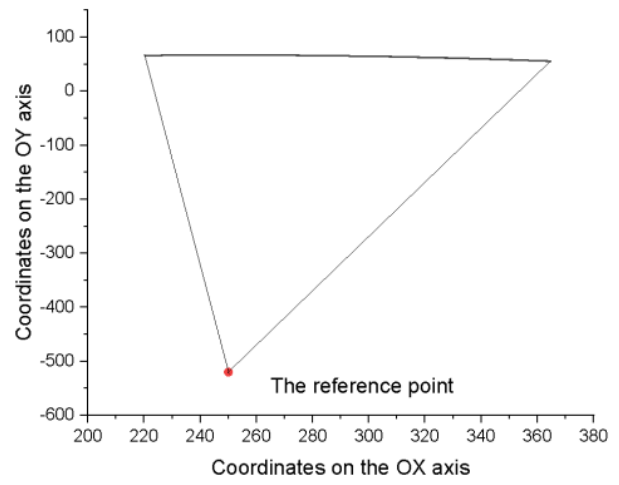

c) $45^{\circ}$

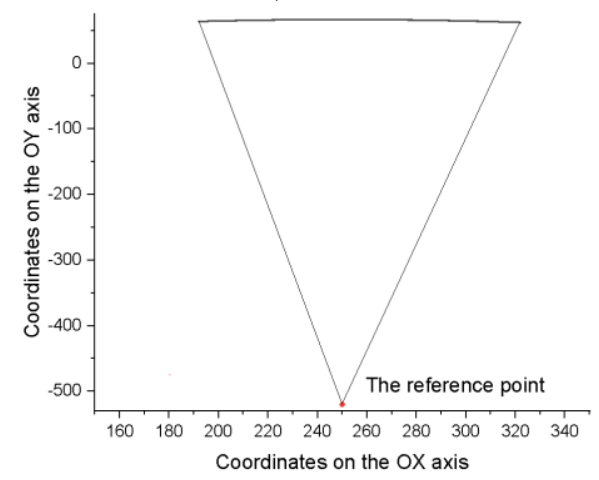

e) $13^{\circ}$

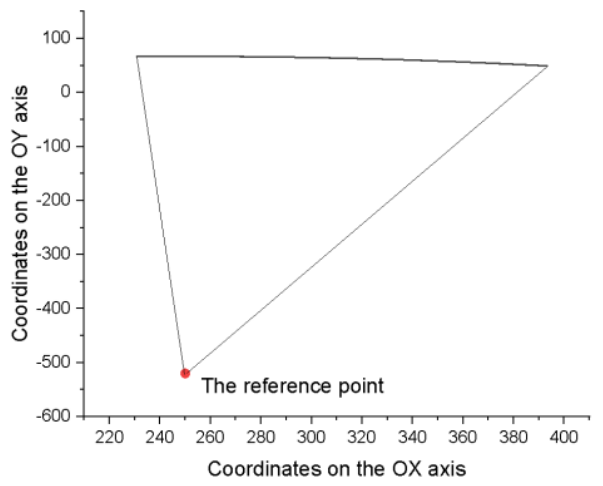

b) $60^{\circ}$

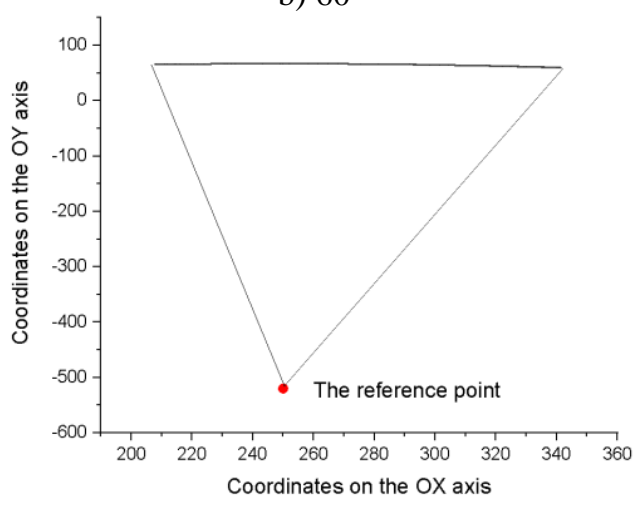

d) $30^{\circ}$

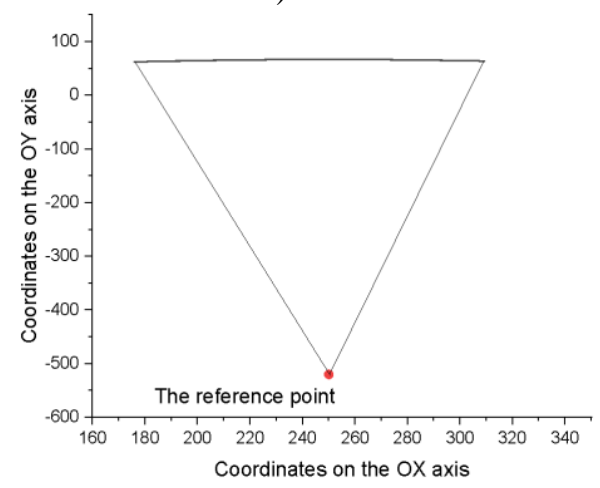

f) $0^{\circ}$ 


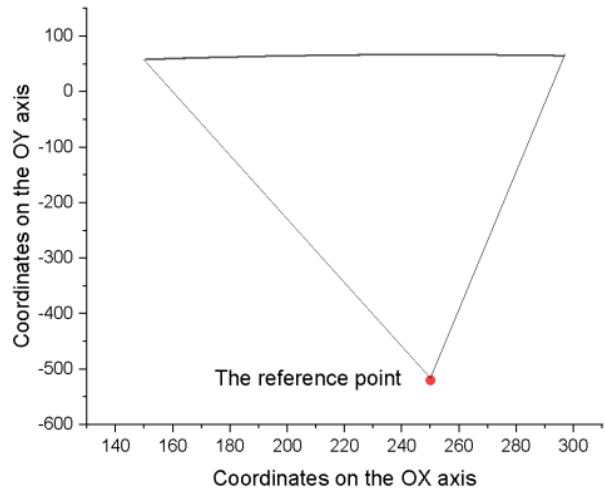

g) $-15^{\circ}$

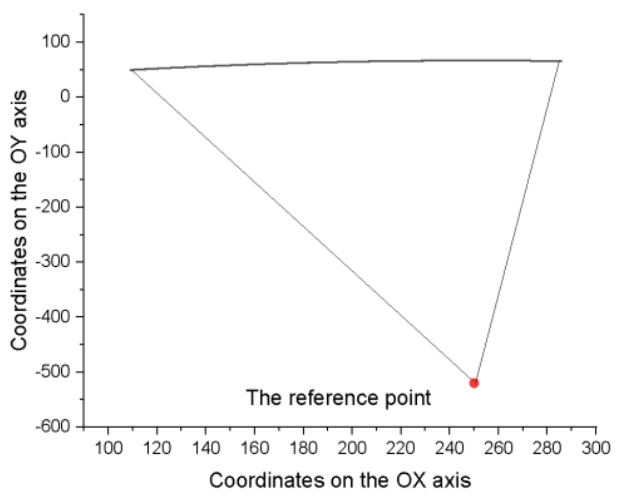

h) $-30^{\circ}$;

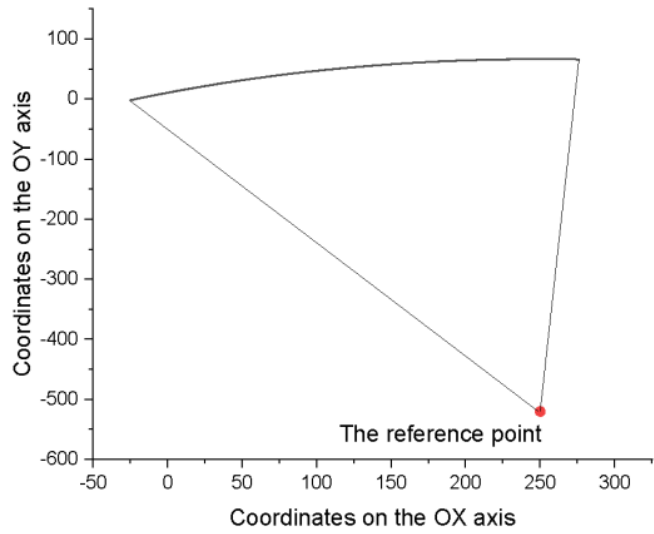

i) $-45^{\circ}$;

Fig. 8. Variation of the angle described by the tie rod according to the position of the drive device: a) $75^{\circ}$; b) $60^{\circ}$; c) $45^{\circ}$; d) $30^{\circ}$; e) $13^{\circ}$ s; f) $0^{\circ}$; g) $-15^{\circ}$; h) $-30^{\circ}$; i) $-45^{\circ}$.

From the analysis of the variation of the angle described by the tie rods, depending on the position of the drive device, the following aspects can be evidenced:

- The angle described by the two extreme positions of the free end of the tie rod was analyzed according to the starting position of the study, respectively the position of the tie rod, being $90^{\circ}$.

- In relation to this position, it is found that the angle described by the tie rod varies in value. This is highlighted by the variations of the angles on the right and left side of the tie rod, respectively the angle $\alpha$ and the angle $\beta$ (Figure 8).

- In relation to the position of the drive device it is observed that the position of the angle varies, as follows:

- For the value of $13^{\circ}$ the values of the angles $\alpha$ and $\beta$ are approximately equal, this value being corresponding for a symmetrical displacement of the free end of the tie rod in relation to the starting position of the displacement.

- When changing the position of the drive device from the value of the angle of $30^{\circ}$ to the value of the angle of $75^{\circ}$ it is observed that the spring described by the free end of the tie rod moves to the right.

$\circ$ For values of the connecting rod angle $\mathrm{c}$ between $0^{\circ}$ and $-45^{\circ}$ it is found that the free end of the tie rod generates an angle that moves to the left.

Analyzing the positions of the extreme points, obtained from the displacement of the free end of the tie rod, P1 and $\mathrm{P} 2$, and of the fixed end of the tie rod, it was possible to determine the angular value between the three points. The variation of this angle is shown in Figure 9.

The analysis of the individual values of the two angles, $\alpha$ and $\beta$, is given in graphical representation from Figure 10. 
Analyzing the angular values presented (Fig. 9) it is found that:

- The smallest angular opening, of $12.71^{\circ}$, corresponds to the connecting rod angle of $13^{\circ}$;

- For the variation of the connecting rod angle between $30^{\circ}$ and $75^{\circ}$, an exponential increase of the value of the studied angle was obtained, reaching the maximum value of $17.78^{\circ}$;

- For the variation of the connecting rod angle between $0^{\circ}$ and $-30^{\circ}$, the same exponential increase of the value of the studied angle was found, obtaining for the last value an angle of $17.49^{\circ}$;

- A specific analysis can be performed for the connecting rod angle of $-45^{\circ}$ where it is found that the calculated angle has a value of $30.5^{\circ}$. This value is due to the positioning of the crank in relation to the driven assembly.

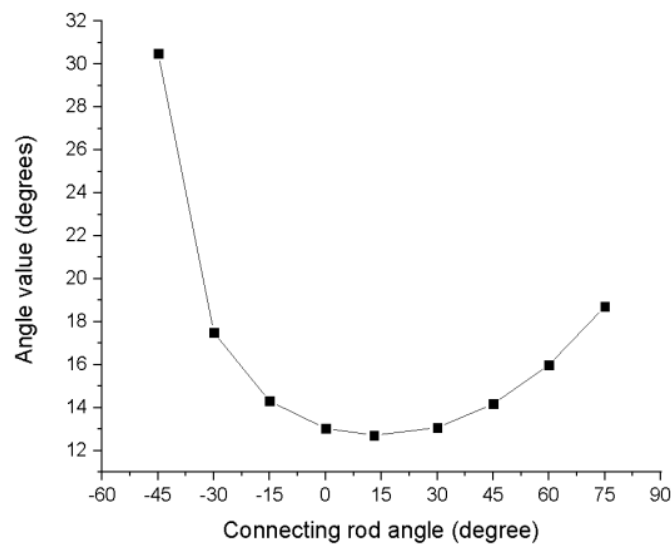

Fig. 9. Variation of the angle described by the free end of the tie rod.

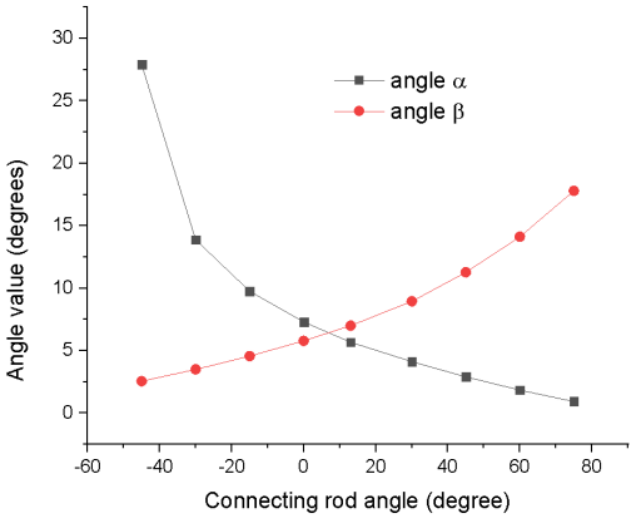

Fig. 10. Variation of angles $\alpha$ and $\beta$.

From the study of the results presented in figure 10 it can be concluded:

- The two angles analyzed, $\alpha$ and $\beta$, have equal values, of approximately $6.4^{\circ}$, for a connecting rod angle in relation to the horizontal of approximately $6.5^{\circ}$. This value of the angle is closely related to the dimensional values of the components that make up the analyzed mechanism;

- The increase of the connecting rod angle in relation to the horizontal, it is found that the values of the angle $\alpha$ decrease, and the values of the angle $\beta$ increase;

- In case of reduction of the connecting rod angle in relation to the horizontal (for negative values of the angle) the value variation of the analyzed angles is reversed.

It was also determined the value of the angle made by the connecting rod in relation to the horizontal, for the two extreme points, P1 and P2. The variation of these angles is shown in Figure 11.

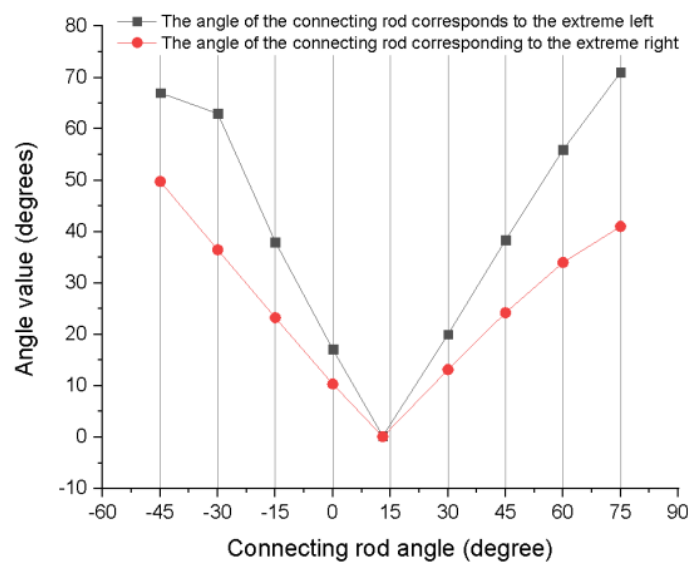

Fig. 11. Angle variation of the connecting rod in relation to the horizontal for the extreme points. 
The following conclusions can be drawn from the analysis of the variation of the two studied angles:

- The value of the angle corresponding to point P1 is greater than the value of the angle P2 regardless of the position of the connecting rod;

- The minimum value of the two angles, of $0^{\circ}$, corresponds to an initial angle, of inclination of the connecting rod, of $13^{\circ}$;

- As the value of the inclination angle of the connecting rod increases, it is found that the values of the two angles also increase, this increase being a linear increase.

\section{CONCLUSIONS}

Following the study performed on the influence exerted by the position of the drive device of an oscillating sieve, the following conclusions could be drawn:

- A number of methods can be used to carry out the process of mechanical separation of a heterogeneous mixture of solid particles;

- One of the most used methods of mechanical separation is the separation on sieves, respectively the dimensional separation of the mixture of solid particles;

- In order to streamline the separation process on sieves, they must perform a series of movements that can be simple or complex;

- The simplest method of driving a sieves block is the oscillating movement, a movement performed by a crank connecting rod mechanism;

- The solid particles movement on the surface of the oscillating sieve is influenced by the angle of inclination of the sieve but also by the movement made by the support system of the sieve block;

- Study of the movement performed by the oscillating sieve, a series of simulations were performed through the Linkage program;

- In order to carry out this study, the initial angle of the connecting rod was modified and in relation to it the following parameters were studied:

- The angle achieved by the movement of the free end of the tie rod, angle obtained by summing the angles $\alpha$ and $\beta$;

- The angles made by the connecting rod corresponding to the two extreme points of the movement made by the free end of the tie rod.

- Following the study, it was found that:

- The initial angle variation of the connecting rod in relation to the horizontal directly influences both the value of the angle made by the free end of the tie rod and the angles made by the connecting rod in relation to the horizontal, for the two extreme points P1 and P2;

- For an angle value made by the connecting rod with a horizontal of $12.71^{\circ}$, the smallest angular opening made by the tie rod was obtained in the case under study. Starting from this point, the value of the angle described by the free end of the tie rod increases in direct proportion to the value of the connecting rod angle;

- The two angles analyzed, $\alpha$ and $\beta$, have equal values, of approximately $6.4^{\circ}$, for a connecting rod angle in relation to the horizontal of approximately $6.5^{\circ}$;

- A minimum value of the two angles described by the connecting rod in relation to the horizontal corresponding to the extreme points $\mathrm{P} 1$ and $\mathrm{P} 2$, respectively $0^{\circ}$, corresponds to an initial angle of inclination of the connecting rod in relation to the horizontal of $13^{\circ}$;

- The variation of the angles described by the connecting rod in relation to the horizontal, corresponding to the extreme points $\mathrm{P} 1$ and $\mathrm{P} 2$, is directly proportional to the variation of the angle of the connecting rod in relation to the horizontal.

This study can be continued by identifying the value of the entrainment speed of a solid particle positioned on the oscillating surface, respectively determining the inertial force generated by the working surface on the solid particle, and then identifying the working regime of the oscillating surface.

\section{REFERENCES}

[1] Bernotat, S., Gregor, W., Some aspects about separation in a cross-flow air-classifier, Chemical Engineering Science, vol. 33, no. 6, 1978, p. 751-757. 
[2] Innocentini, M.D.M., Barizan, W.S., Alves, M.N.O., Pneumatic separation of hulls and meats from cracked soybeans, Food and Bioproducts Processing, vol. 87, no. 4, 2009, p. 237-246.

[3] Yoshida, H., Saeki, T., Fujioka, T., Ueda, T., Fuyuki, T., Fine-particle separation by revised type air-cyclone classifier, Kagaku Kogaku Ronbunshu, vol. 19, no. 3, 1993, p. 476-482.

[4] Nedeff, V., Mosnegutu, E., Savin, C., Katalinic, B., Influence of particles condition surface and humidity of mixture, towards separation degree in vertical flow air, Annals of DAAAM for 2003 \& Proceedings of the 14th International DAAAM Symposium, 2003, p. 323-324.

[5] Nedeff, V., Lazar, G., Agop, M., Mosnegutu, E., Ristea, M., Ochiuz, L.C.M., Eva, L., Popa, C., Non-linear behaviours in complex fluid dynamics via non-differentiability, Separation control of the solid components from heterogeneous mixtures, Powder Technology, vol. 269, 2014, p. 452-460.

[6] Nedeff, V., Lazar, G., Agop, M., Eva, L., Ochiuz, L., Dimitriu, D., Vrajitoriu, L., Popa, C., Solid components separation from heterogeneous mixtures through turbulence control, Powder Technology, vol. 284, 2015, p. 170186.

[7] Macpherson, S.A., Iveson, S.M., Galvin, K.P., Density based separations in the reflux classifier with an airsand dense-medium and vibration, Minerals Engineering, vol. 23, no. 2, 2010, p. 74-82.

[8] Mosnegutu, E., Nedeff, V., Bontas, O., Barsan, N., Chitimus, D., Possibilities to determining the solid particle trajectories on an oscillating separation screen, Journal of Engineering Studies and Research, vol. 20, no. No. 3, 2014, p. 63-69.

[9] Panasiewicz, M., Kazimierz, Z., Elżbieta, K., Paweł, S., Purification and separation of loose materials in a pneumatic system with vertical air stream, TEKA Kom. Mot. Energ. Roln. - OL PAN, vol. 8, 2008, p. 171-176. [10] Ogawa, A., Separation of particles from air and gases, vol I si II. CRC Press, Inc, Boca Raon, Florida, 1984. [11] Xing, W.J., Wang, Y.Z., Zhang, Y., Yamane, Y., Saga, M., Lu, J.F., Zhang, H., Jin, Y., Experimental study on velocity field between two adjacent blades and gas-solid separation of a turbo air classifier, Powder Technology, vol. 286, 2015, p. 240-245.

[12] Pruteanu, A., Matache, M., Muscalu, A., David, L., Research of technological process for medicinal plant separation, Engineering for Rural Development, 2017, vol. 16, p. 892-897.

[13] Phillip, C.W., Separation process engineering, Prentice Hall, 2012.

[14] Grandison, A.S., Lewis, M.J., Separation processes in the food and biotechnology industries, Woodhead Publishing, 1996.

[15] SMICO Manufacturing Co., Vibrating screen design \& its effect on screen motion, https://www.youtube.com/watch?v=h81WpT_nDIE (12.01.2021).

[16] Shuen Li MAchinery Co., Horizontal vibrating sieving machine, https://shuenli.en.taiwantrade.com/product/horizontal-vibrating-sieving-machine-324852.html (12.01.2021).

[17] Lackeby Probuscts, Lackeby Roto-Sieve drumscreen, https://www.youtube.com/watch?v=dA1xMDs47Fk (12.01.2021).

[18] Osttiroles Getreidentuhlen, Osttiroler grain mills: commercial mill, https://www.getreidemuehlen.com/en/grain-mills/commercial-mills/commercial-mills.php (12.01.2021).

[19] Peng, L., Feng, H., Wang, Z., Wang, H., Yang, H., Huang, H., Screening mechanism and properties of a cantilevered vibrating sieve for particles processing, Applied Sciences, vol. 9, no. 22, 2019.

[20] Voicu, G., Stoica, D., Constantin, G., Carp-Ciocardia, D.-C., Stefan, E.-M., Influence of the granular mixture particles sizes and oscillation frequency on the separation process at the conical sieves with oscillating movement, Journal of Engineering Studies and Research, vol. 20, 2014.

[21] Mosnegutu, E., Nedeff, V., Narcis, B., Chitimus, D., Rusu, D.I., Influence of screening block supporting way on the behaviour of a solid particle on an oscillating surface, Journal of Engineering Studies and Research, vol. 21, 2016.

[22] Hartenberg R., Denavit J., Kinematic synthesis of Linkages. McGraw Hill Book Company, N.Y, 1964.

[23] Goessner, S., Crank-rocker-Design and analysis, https://github.com/goessner/crocker\#readme (12.01.2021).

[24] Natesan, A.K., Kinematic analysis and synthesis of four-bar mechanisms for straight line coupler curves, Rochester Institute of Technology, 1994.

[25] Sharifgalieva, I., The design and simulation of mechanisms, Arcada University of Applied Sciences, 2018. 